\title{
Senvicio doméstico y maternidad en los legajos de menores: nuevas preguntas y perspectivas historiográficas (Buenos Aires, 1940-1950)
}

Domestic service and motherhood in the files of minors: new questions and historiographical perspectives (Buenos Aires, 1940-1950)

Inés Pérez

CONICET, Argentina

inesp18@yahoo.com

\section{Resumen:}

Este artículo muestra que los legajos de menores abiertos por la Sociedad de Beneficencia de la Capital ofrecen material relevante para abordar las experiencias de maternidad de las trabajadoras domésticas en la Buenos Aires de las décadas centrales del siglo XX. En particular, se sostiene que esta fuente no solo permite analizar las circunstancias en las que esas experiencias tuvieron lugar, sino la agencia de las trabajadoras, su capacidad para desarrollar estrategias de cuidado hacia sus hijos y, aún más, incidir en sus trayectorias dentro del sistema de minoridad.

Palabras clave: Servicio doméstico, Maternidad, Legajos de menores.

\section{Abstract:}

This article shows that the files of minors opened by the Sociedad de Beneficencia de la Capital offer relevant material to address domestic workers' experiences of maternity in the middle decades of the 20th century Buenos Aires. In particular, it is argued that this source not only allows the analysis of the circumstances in which those experiences took place, but also the workers' agency, their capacity to develop care strategies for their children and, even more, to have an impact in their trajectories within the minority system.

KEYWORDS: Domestic service, Moderhood, Files of minors.

\section{INTRODUCCIÓN}

El 18 de marzo de 1949, Rita y Mabel Quintana, de 9 y 11 años, fueron admitidas en un hogar de niñas ${ }^{1}$. Su madre, Jacinta M. de Quintana así lo había solicitado algún tiempo antes ante la Sociedad de Beneficencia de la Capital (SB) ${ }^{2}$. El motivo: la falta de recursos y el hecho de tener que "salir de su trabajo" para ocuparse de ellas. Las niñas ingresaron en el Hogar Saturnino Unzué de Mar del Plata, en donde permanecieron hasta 1953. Sin embargo, Jacinta no dejó de visitarlas periódicamente, aunque no con mucha frecuencia: ella vivía en Buenos Aires y para viajar a Mar del Plata (400 Km al sur de la capital) necesitaba dinero para el pasaje y el permiso de sus empleadores. Jacinta trabajaba como empleada doméstica. En varias oportunidades solicitó a las autoridades que trasladasen a las niñas a algún hogar más cercano. En una de ellas, en abril de 1951, envió una carta al "Director de Menores", en la que contaba que la última vez que las había visitado, en agosto del año anterior, había tenido que dormir en una estación de servicio porque no podía pagar un hotel. En su carta, se lee:

...ruegole me aga esa carida me los traslade a la Capital o cualquier parte mas serca de poder viajar lo unico le pido las 2 juntas. Agame señor esa caridad que tengo ganas de verlas se que estan vien pero ase 7 meses no puedo ir. Sin mas desde ya muy agradecida y esperando su caridad que le pido con el ferbor y cariño de una madre pobre ${ }^{3}$.

Recepción: 11 de diciembre de 2018 | Aprobación: 22 de abril de 2019 | Publicación: 28 de mayo de 2019

Cita sugerida: Pérez, I. (2019). Servicio doméstico y maternidad en los legajos de menores: nuevas preguntas y perspectivas historiográficas (Buenos Aires, 1940-1950). Anuario del Instituto de Historia Argentina, 19 (1), e086. https://doi.org/10.24215/2314257Xe086 
Por la irregularidad de la letra, las faltas de ortografía y las de puntuación, la carta muestra que Jacinta no estaba habituada a escribir, aunque sabía hacerlo y conocía las fórmulas retóricas adecuadas a sus propósitos. ¿Qué sentido tenía para alguien como Jacinta hacer referencia al "fervor y el cariño de una madre pobre"? Desde hace décadas los estudios históricos han mostrado que la institucionalización de los niños y niñas no siempre suponía la ruptura de los lazos con sus familias, ni una falta de afecto hacia ellos (Fuchs, 2003; Cicerchia, 1994; Dalla-Corte Caballero, 2013; Milanich, 2009; Blum, 2009). Al contrario, distintas investigaciones mostraron que dicha institucionalización podía formar parte de estrategias para hacer frente a magras condiciones materiales de vida, y que las familias muchas veces tenían la expectativa de recuperarlos luego de un tiempo. Incluso se ha mostrado que aunque esta práctica se apartaba del modelo normativo, muchas veces las mujeres que solicitaban la internación de sus hijos lo hacían mostrándose como madres buenas que solo realizaban ese pedido por las difíciles condiciones en las que vivían. ¿Qué significaba para una mujer que trabajaba como empleada doméstica internar a sus hijas? ¿Qué alternativas tenía? ¿Qué limitaciones suponía este tipo de trabajo para las formas en que podían vivir la maternidad quienes lo desempeñaban?

Conocemos la historia de Jacinta a partir de los legajos de sus hijas iniciados por la SB. Jacinta es una figura central en ellos: sus declaraciones y peticiones, las evaluaciones que de ella hacen las visitadoras y autoridades son cruciales para comprender la trayectoria de sus hijas en las instituciones de minoridad. En este artículo problematizo las posibilidades que brindan los legajos de menores para abordar las experiencias de la maternidad de mujeres trabajadoras, y en particular las de quienes se desempeñaban en el servicio doméstico. Para seguir la línea de este dossier, la discusión propuesta girará en torno de las lecturas que se han hecho de estas fuentes históricas y las posibilidades que brindan cuando son utilizadas para pensar otras preguntas.

Los legajos de menores han sido solo recientemente abiertos a la consulta pública, pero forman parte del archivo de la SB, que ha sido utilizado por numerosas investigaciones. Si ellas abonaron a distintos campos historiográficos, como la historia de la infancia y la minoridad, la del Estado y los derechos sociales, la de las mujeres y su participación en la vida pública, en este artículo, en cambio, buscaré mostrar que dicho archivo también puede arrojar luz sobre las negociaciones sobre los ideales de maternidad y familia entre distintos actores, así como sobre las experiencias de las trabajadoras, en particular las que se desempeñaban en el servicio doméstico en la ciudad de Buenos Aires de mediados del siglo XX.

A diferencia de otras fuentes que han sido analizadas para construir la historia de los modelos y prácticas de maternidad y de familia, los legajos tienen registros (aunque mediados, sesgados y muchas veces indirectos) de distintas voces y miradas, que incluyen las de las propias madres y, en algunos casos, las de los niños y las niñas. En este texto argumentaré que los legajos de menores permiten volver sobre dos cuestiones largamente abordadas por la historiografía -como las condiciones materiales de vida de las trabajadoras y los trabajadores, y las experiencias de la maternidad-, pero para plantear preguntas novedosas. Sostendré que habilitan la construcción de una mirada articulada entre los mundos del trabajo y la familia, sobre sus condicionamientos y solapamientos, y sobre la relevancia de ambos en la vida de mujeres como Jacinta.

A partir del caso de Jacinta -que los registros siguen desde fines de los años cuarenta a mediados de los cincuenta ${ }^{4}$-, mostraré que los legajos de menores permiten ver que el empleo en el sector doméstico, en muchos casos sin retiro, imprimía limitaciones concretas a las posibilidades de las trabajadoras de vivir con sus hijos. Si bien esto no siempre suponía el quiebre de esos vínculos, sí establecía condiciones particulares para el desarrollo de esas relaciones y para las experiencias de la maternidad de las trabajadoras. Los legajos, en este sentido, no solo permiten reconstruir las circunstancias en las que esas experiencias se desarrollaban, sino la agencia de las trabajadoras, la capacidad que tenían las mismas para desarrollar estrategias de cuidado hacia sus hijos, y, más aún, para incidir en sus trayectorias dentro del sistema de minoridad.

En lo que sigue presentaré algunas de las investigaciones que han utilizado este archivo y las líneas historiográficas a las que han contribuido. Luego, me detendré en las características particulares de los legajos de menores, en la documentación que reúnen y en los desafíos metodológicos que presentan, para más 
tarde considerar las posibilidades que brindan al momento de abordar las experiencias de maternidad de las trabajadoras domésticas. A partir de ellas, en la sección final del artículo expondré algunos de los interrogantes que me despertó el trabajo con estas fuentes y su relevancia para pensar la historia social con perspectiva de género.

\section{El archivo de la Sociedad de Beneficencia de la Capital en la historiografía ARGENTINA}

Los legajos de menores que discuto en este artículo forman parte del archivo de la SB, que es excepcionalmente rico 5 . La SB fue creada en 1823 por el entonces presidente Bernardino Rivadavia y su gestión fue encargada a un grupo de mujeres de la elite porteña. Tuvo un importante papel en la administración de distintas instituciones de caridad y beneficencia. Entre las muchas instituciones bajo su órbita se encontraban hospitales, hospicios y asilos. Su accionar a lo largo de más de un siglo tuvo una incidencia insoslayable en la vida de los sectores populares. En 1946, fue intervenida por el gobierno peronista, y fue disuelta en 1948. La longevidad de esta institución y su gravitación en la sociedad argentina explican que su historia haya sido trabajada por numerosas investigaciones; la densidad de su archivo, por su parte, explica el hecho de que haya servido de apoyo para pensar una amplia diversidad de problemas historiográficos.

Una clave de lectura que se apoya en este archivo es la que considera a la SB como parte de lo que José Luis Moreno (2000) llamó "la política social antes de la política social". Si en las décadas de 1980 y 1990 la producción historiográfica sobre las políticas sociales se había centrado en la segunda mitad del siglo XX -en particular en el período de los dos primeros gobiernos peronistas-, a partir de inicios del siglo XXI las y los historiadores comenzaron a dar una mayor relevancia a las etapas previas. Estas investigaciones permitieron mostrar la larga construcción del Estado Social y la intervención de distintos agentes en ese proceso. En esta línea, se destacó la relevancia y funcionalidad de las organizaciones "tradicionales" en el desarrollo del Estado de Bienestar y las políticas sociales "modernas" (Guy, 2011).

Estos abordajes mostraron la historicidad del Estado social, al señalar la presencia de políticas sociales desde la época colonial, al tiempo que evidenciaron la intervención de actores "de distinta naturaleza, con motivaciones, intereses, prácticas y dinámicas propias" en su gestación (Remedi, 2009, p. 92). La SB ha tenido un lugar clave en esta historia, por su lugar ambiguo en relación al Estado: si bien su gestión admitía cierto grado de autonomía, su funcionamiento dependía en buena medida del financiamiento estatal. Su análisis permitió mostrar su actuación como brazo asistencial del Estado (Pita, 2012), al tiempo que dio lugar al señalamiento de sus limitaciones, en el marco de lo que Lucía Bracamonte (2015) identificara como la "economía mixta de la asistencia".

Como han mostrado distintas investigaciones, la delimitación de los sujetos y las formas de intervención de la SB fueron resultado de intensas disputas con una multiplicidad de actores dentro del Estado y de la sociedad civil (Moreno, 2000; Facciuto, 2003; Suriano, 2004; Remedi, 2009; Golbert \& Roca, 2010). A partir del análisis de su organización interna, las formas de intervención, los saberes que la fundaban y las prioridades establecidas en uno y otro momento, distintas investigaciones señalaron los modos en que la SB contribuyó a la construcción de la cuestión social. Ahora bien, si hasta la década de 1990 predominaron los enfoques que ponían el acento en el control social generado por estos dispositivos de intervención, en las últimas décadas han cobrado relevancia las estrategias y los usos instrumentales de las y los "asistidos" (Moreyra, 2009). La riqueza del archivo de la SB ha permitido también avanzar en términos interpretativos más allá de la historia institucional, para hacer foco en las demandas, estrategias, experiencias, y sobre todo en la agencia histórica de aquellas personas que recurrían a las instituciones bajo su órbita (Pita, 2009; 2012; 2015).

El archivo de la SB también fue usado para señalar el lugar de las mujeres en la construcción del Estado social, aunque también este punto fue objeto de debate. Hasta los años noventa, la producción historiográfica había asumido que la actuación de las mujeres de la elite en las instituciones de beneficencia había reforzado 
los papeles tradicionales de género al resaltar su asociación con la maternidad y su lugar de cuidadoras de niños y enfermos. Sin embargo, diversas investigaciones posteriores han mostrado que las instituciones de beneficencia, tanto la SB de la capital como otras en otras regiones del país, permitieron a las mujeres de la elite trascender las fronteras de lo doméstico para encontrar medios de ejercer la ciudadanía sin cuestionar los modelos de género dominantes (Ciafardo, 1990; García Jordán y Dalla Corte Caballero, 2006; de Paz Trueba, 2010; Bracamonte, 2012).

La relevancia de las acciones desarrolladas por la SB ha hecho que su archivo tuviera un lugar clave en diversos campos historiográficos. En este texto interesa destacar su papel en la historia de la infancia, y, en particular, del trabajo infantil. Como ha mostrado Carolina Zapiola (2010), el avance de la mirada positivista y de los poderes del Estado en relación a la situación de ciertos niños hacia fines del siglo XIX y en las primeras décadas del XX no implicó una pérdida de autoridad de las instituciones de beneficencia. El archivo de la SB ha permitido abordar las formas de intervención en ese campo, historizar los cambios en la definición y los límites de la autoridad parental, el lugar del vínculo biológico en la construcción del parentesco, y los supuestos que permitían plantear su disolución (Villalta, 2012; Zapiola, 2014). También ha permitido analizar la circulación de niños y niñas, y su colocación tanto laboral como familiar.

El estudio de dicha circulación tiene una relevancia que trasciende el campo de la historia de la infancia y se imbrica con el de los estudios del trabajo. Investigaciones recientes han enfocado la mirada en distintas formas de trabajo infantil reconstruidas a partir del archivo de la SB. Estas investigaciones no solo señalaron su importancia para pensar ocupaciones particulares, como el servicio doméstico, sino que marcaron los límites de la mercantilización del trabajo y su coexistencia con formas de trabajo no libre todavía en las primeras décadas del siglo XX (Aversa, 2014; Allemandi, 2017).

Los problemas y perspectivas historiográficas desarrolladas a partir de este archivo son múltiples. La apertura a la consulta de nueva documentación permite avanzar en otros sentidos. En particular -sostendré aquí- permiten pensar la historia social del trabajo desde una perspectiva de género. Aunque los legajos fueron cambiando a lo largo del tiempo, aquellos iniciados a fines de los años cuarenta permiten pensar las trayectorias laborales y familiares de manera conjunta, en una apuesta que implica trascender los límites androcéntricos con los que habitualmente se piensa la categoría "trabajo". El abordaje de las experiencias de maternidad de las trabajadoras domésticas que acudían a la asistencia pública para resolver el cuidado de sus hijos - cuyo trabajo remunerado era realizado dentro de un hogar privado (el de los empleadores) y el no remunerado estaba mediado institucionalmente - tensiona aún más el sesgo androcéntrico implícito en dicha categoría y los interrogantes historiográficos que a partir de ella pueden plantearse. ¿Qué posibilidades tenían quienes se empleaban en el servicio doméstico para conciliar el trabajo que realizaban para sus empleadores y el cuidado que requerían sus propios hijos? ¿Qué implicaba para ellas ese cuidado? ¿En qué medida suponía una negociación en torno de los modelos de maternidad hegemónicos?

Antes de explorar las preguntas que surgen de este tipo de experiencias, conviene, sin embargo, presentar algunas de las características más salientes de los legajos y los problemas metodológicos que plantean. A ello dedicaré el siguiente apartado.

\section{LOS LEGAJOS DE MENORES COMO FUENTE HISTÓRICA}

Cada vez que un niño o niña era internado en alguna de las instituciones dependientes de la SB se abría un legajo. Se iniciaba con una solicitud de internación, a la que luego se agregaban distintos documentos (informes médicos, ambientales, certificados de nacimiento, matrimonio, etc.). En ellos se reunía toda la información producida en torno a ese niño o niña hasta que salía del sistema. En los casos en los que era entregado/a a una familia -en una colocación que podía ser o no laboral-se hacían informes periódicos que eran incluidos allí. También se registraban visitas, traslados y vacaciones, se guardaba la correspondencia, se incluían las evaluaciones docentes, los registros hospitalarios y los informes médicos. En el fondo documental 
se conservan 960 cajas, cada una de las cuales tiene entre 20 y 30 legajos. El último de los legajos que consulté está numerado como 59.996. Aunque no es posible saber cuándo se inició esa numeración correlativa, puesto que aún no se abrieron y catalogaron todas las cajas, este número nos da idea del volumen de legajos conservado.

Yo llegué a ellos buscando casos de colocaciones domésticas ${ }^{6}$. Como mi intención era hacer dialogar esas experiencias con otras enmarcadas en el servicio doméstico en las décadas centrales del siglo XX, comencé a trabajar con los más recientes, iniciados en los primeros meses de 1949. Hasta el momento revisé alrededor de 150 legajos, todos ellos correlativos, todos abiertos entre 1947 y 1949. Es difícil saber cuántos fueron abiertos durante el peronismo y cuántos son anteriores, puesto que no sabemos si la cantidad de pedidos de internación se mantuvo estable a lo largo del tiempo. Sí es posible saber, en cambio, que aquellos legajos iniciados durante el peronismo presentan algunas particularidades: desde la intervención de la SB, en 1946, se permitieron las visitas de los progenitores de los niños y las niñas internadas en las instituciones que de ella dependían. Los cambios introducidos por el peronismo en las políticas hacia la infancia habilitaron, en este sentido, una mayor presencia de los familiares de las niñas y los niños internados en sus legajos, a través del registro de sus visitas y cartas, y de los informes periódicos que se realizaban para establecer si estaban o no en condiciones de sostener una eventual reunificación familiar. Algunos legajos llegan hasta fines de los años sesenta, puesto que, como se dijo arriba, siguen a las niñas, los niños y jóvenes hasta su salida del sistema, que en algunos casos solo ocurría al cumplir la mayoría de edad. En este sentido, están atravesados por importantes cambios sociales e institucionales, como la creación de la Dirección Nacional de Asistencia Pública durante el gobierno peronista, y del Consejo Nacional del Menor, durante el desarrollismo, así como de otras transformaciones, como la profesionalización del trabajo social en los sesenta (Villalta, 2012).

La mayor parte de los legajos iniciados en los últimos tiempos de la SB cuentan con informes ambientales. Si cubren un largo período de tiempo, suele haber más de uno. El primero, por lo general, es inmediato al pedido de internación del menor o de la menor y consiste en la descripción de las condiciones de vida del grupo familiar con el que el niño o la niña vivía hasta entonces. Se describe la vivienda, la conformación del grupo doméstico y sus ingresos. Estos legajos permiten saber si otros adultos formaban parte del grupo familiar y si contribuían o no económicamente a su sostenimiento. En muchos casos se indica, además, si existían otros parientes que dependían del hogar, aunque no convivieran con el resto de la familia. En ocasiones se revelaba el lugar de nacimiento del niño o la niña e incluso de sus padres, lo que muestra si había habido migraciones y dónde se originaron (la más de las veces en pequeñas localidades de las provincias). Uno de los datos más interesantes que allí se relevaban es si el niño o la niña internada tenía hermanos, dónde y con quién vivían, si trabajaban o no. Como los informes eran realizados con periodicidad, registraban cambios tanto en la conformación del grupo doméstico como en las trayectorias laborales de quienes lo conformaban.

Más allá de las condiciones materiales de vida, en algunas ocasiones los informes ambientales permiten observar otras cosas. Quienes los escribían evaluaban la situación observada y prescribían cursos de acción. Por su parte, las personas acerca de las que se informaba adecuaban su discurso para lograr sus propósitos. El registro del encuentro o desencuentro entre las expectativas de unos y otras es en sí mismo significativo: en ellos conviven distintas voces, aunque no con la misma claridad ni en un pie de igualdad.

Los informes conservados en los legajos de la SB no siempre están firmados ni se indica el nombre de quien los realizó. Los hay escritos tanto por varones como por mujeres. Aunque no siempre es posible saberlo con certeza, es probable que hayan sido realizados por visitadoras y luego asistentes sociales. El trabajo social vivió un proceso de profesionalización desde los años veinte y treinta, con la creación de carreras específicas, inicialmente muy cercanas a la Medicina (Alayón, 1992). De acuerdo a Donna Guy (2011), ese proceso se intensificó a partir de los años cuarenta, con un giro hacia otros saberes, como la psicología y el derecho, y con una mayor presencia en las instituciones de menores. Ese proceso estuvo marcado, además, por una feminización de esta profesión (Gavrila, 2018). 
Como los cuadernos de las visitadoras de higiene ya trabajados en otras investigaciones (Di Liscia y Billorou, 2005; Billorou, 2008), los informes registran en un primer plano las voces de quienes los escribían, y permiten rastrear cambios en sus trayectorias formativas y profesionales. También muestran tensiones entre diferentes agentes que intervenían en la vida de los niños, niñas y jóvenes cuyos legajos se conservan: por un lado, en algunos casos existen informes realizados por distintas personas que registran miradas contrastantes respecto de la misma situación; en otros, es posible ver que las recomendaciones puntualizadas allí eran desoídas por quienes eran responsables de tomar decisiones.

$\mathrm{Al}$ mismo tiempo, aunque tamizadas por la mirada de quienes escribían, los informes registran prácticas y voces de quienes eran evaluados. La historia social ha utilizado largamente los registros oficiales para rastrear la agencia histórica de los sectores populares, en lecturas a contrapelo de fuentes municipales, policiales, judiciales, médicas, entre otras (ver, por ejemplo, Andújar et al., 2016). En ese tipo de abordajes, la "apatía" de aquellos cuyas prácticas buscaban modificarse, registrada de ese modo por las visitadoras y asistentes sociales, ha sido, en cambio, leída como resistencia; su "ignorancia", como contraposición entre saberes y representaciones no solo distintos, sino con desigual legitimidad (Billorou, 2007; Pita, 2014).

En los legajos también incluyen otros documentos en los que las voces de los y las actoras que acudían a la SB están menos mediados, como cartas. Las que se conservan suelen ser las que los familiares le enviaban a los niños y las niñas internadas. En ellas se narran episodios excepcionales dentro de una cotidianeidad a la que solo se refiere tangencialmente (Stanley, 2004). Las más de las veces, anunciaban una próxima visita; otras, acompañaban un obsequio: algún dulce o golosina, una prenda, etc. Sin embargo, el contenido central de las cartas era más bien otro: la afirmación del afecto.

Como aquellas que enviaban los migrantes a los parientes que habían dejado en su lugar de origen, las que se conservan en los legajos de menores tenían un papel clave en el sostenimiento de los vínculos familiares. Micaela di Leonardo (1987) desarrolló el concepto de trabajo de parentesco para dar cuenta de las actividades que permiten la construcción, el mantenimiento y la celebración ritual de los lazos entre familiares y amigos que no viven juntos. En esta misma línea, Loretta Baldassar (2008) señaló que las emociones de extrañar y añorar resultaban integrales al trabajo de parentesco necesario para mantener relaciones familiares transnacionales y crear un sentido de copresencia. También en las cartas que se enviaban a los niños y las niñas internadas las emociones tenían un sitio privilegiado: el cariño y el deseo de estar juntos aparecen con frecuencia, al igual que el pesar, cuando las visitas planificadas no pueden realizarse.

A pesar de ello, las cartas no pueden considerarse documentos "privados", al menos no en un sentido estricto. Quienes las enviaban sabían que serían abiertas por las autoridades antes que por sus destinatarios; lo que decían allí tenía en cuenta esa lectura. La mirada de las autoridades se proyectaba sobre lo que escribían. Muchas veces incluían alusiones directas a ellas, o incluso podía pasar que la primera parte de la carta les estuviera explícitamente dirigida. En este sentido, es posible pensar que el lenguaje emocional también fuera utilizado especialmente para afectar la lectura de las autoridades y el personal de las instituciones de minoridad, como un indicativo de que las niñas y los niños que las recibían no habían sido abandonados 7 .

¿Qué se puede leer en los documentos que componen los legajos? ¿Qué dicen respecto de la historia social del trabajo y de las trabajadoras? ¿En qué medida permiten iluminar las articulaciones entre sus trayectorias laborales y familiares? ¿Qué permiten decir, específicamente, sobre las experiencias de maternidad de las trabajadoras domésticas? Abordaré estas preguntas a partir del caso de Jacinta con el que abrí este texto, para luego, en la última sección del artículo, pensar los problemas historiográficos que este tipo de información permite discutir.

\section{EL FERVOR Y EL CARIÑO DE UNA MADRE POBRE}

Cuando la Dirección de Asistencia Social aprobó la admisión de sus hijas en el Hogar Unzué, Jacinta tenía 36 años, estaba separada del padre de sus hijos y se desempeñaba como trabajadora doméstica sin 
retiro en la casa de un matrimonio, los Iturralde, desde hacía siete años. Además de las niñas, tenía otros dos hijos apenas mayores: Nicanor, que le llevaba un año a Rita, y Jaime, tres años mayor. Trabajaba para los mismos empleadores desde 1944. Aunque ellos aceptaban que dos de sus hijos vivieran en su casa, le habían indicado que cuatro eran "demasiados"8. Los Iturralde vivían en un "departamento amplio, compuesto de 6 habitaciones, dotado de todos los elementos modernos de un confortable hogar", y tenían dos hijas, ya mayores de edad ${ }^{9}$. Qué era lo que había cambiado en la situación de Jacinta para que necesitara internar a las niñas no resulta claro. Ante los empleados de la Dirección declaró que, además de sus hijos, tenía a su cargo a una hermana enferma de los pulmones. Posiblemente antes fuera ella quien la ayudaba con el cuidado de sus hijos. Los niños habían nacido en el norte de la provincia de San Luis, en un área escasamente poblada. No sabemos cuánto tiempo hacía que habían migrado a Buenos Aires, aunque lo habían hecho por lo menos siete años antes, sin el marido de Jacinta. En ese tiempo, las niñas habían ido a la escuela y habían tomado la primera comunión.

Aunque desconocemos qué fue de sus hermanos cuando las niñas ingresaron en el Hogar Unzué, es posible que hayan estado un tiempo con Jacinta en casa de sus empleadores, hasta ser internados ellos también en otras instituciones. En una carta de abril de 1951, Jacinta sostenía: "Yo travajo de cosinera en avenida paral [Parral] 1050 piso 3, me tienen con 2 chicos mas". ${ }^{10}$ Sin embargo, según consta en un informe ambiental de mayo de 1951, Jaime, que tenía entonces 17 años, había egresado recientemente del colegio de Pilar, donde había estado internado gratuitamente y donde aún permanecía Nicanor, para empezar a trabajar en una fábrica, mientras vivía con su madre en casa de sus empleadores. Algún tiempo después, en octubre de 1953, era Nicanor quien compartía con ella la habitación en casa de sus empleadores, mientras trabajaba como aprendiz de mecánico. Jacinta dormía en una cama turca; Nicanor, en el suelo. El único otro mobiliario de la habitación era un pequeño ropero. Para ese entonces, Jaime trabajaba como albañil y vivía en San Miguel con su abuela de 84 años, a quien Jacinta ayudaba económicamente (quizás a cambio del lugar que le daba a su hijo mayor).

En la carta citada arriba, que Jacinta le enviara al director de la Asistencia Social, la imagen de la caridad aparece insistentemente, lo que resulta especialmente significativo en un tiempo en el que se la intentó reemplazar por un discurso de derechos. El texto construye una imagen de buena madre vinculada al sacrificio (las dificultades atravesadas para ver a sus hijas), pero también al amor, a las "ganas de verlas", al "fervor y el cariño de una madre pobre". Aunque se había autorizado el traslado de las niñas, se lo dejó sin efecto por falta de vacantes.

No obstante, los registros muestran que Jacinta seguía viajando a Mar del Plata regularmente para visitar a Rita y Mabel, les enviaba cartas, e incluso compartía con ellas algunos períodos de vacaciones. En 1949 las visitó un total de cinco veces, igual que en 1950; en 1951 fue a verlas en ocho ocasiones; en 1952, en seis y en 1953, en doce. En 1954, cuando ya habían sido trasladadas a Buenos Aires, estuvo con ellas todos los domingos. Además, Rita y Mabel pasaban sus vacaciones de verano en casa de los empleadores de su madre. Ellos partían de viaje y las autorizaban a que se quedaran allí, e incluso que durmieran en la habitación de una de sus hijas, "para que las pequeñas se encuentren cómodas y a gusto"11.

De acuerdo al informe de la visitadora, el permiso para que las niñas pasaran sus vacaciones allí se debía "al afecto" que los empleadores sentían por Jacinta, porque era "una mujer honesta, buena y trabajadora" 12 . Ese afecto, sin embargo, estaba marcado por una relación jerárquica, en la que los empleadores se posicionaban en un lugar de superioridad no solo social sino también moral. Consultada por la visitadora, una de las hijas de los empleadores sostuvo que Rita y Mabel querían mucho a los empleadores de Jacinta, y agregaba: "se nota que es la única familia que conocen"13.

Ahora bien, a pesar de los reiterados esfuerzos por verlas, como muchas de las mujeres que solicitaban la internación de sus hijos, Jacinta se negaba a que sus hijas volvieran a vivir con ella. No era solo que no tuviera suficiente espacio o dinero, sino que esperaba que en el instituto en el que estaban recibieran una 
educación que les permitiera tener un futuro mejor. En diciembre de 1953, ante la insistencia de una de las visitadoras (que señalaba que Rita estaba casi por cumplir los 17 años y que si egresaba del hogar podría ayudarla económicamente), Jacinta se "...indignó-, para qué la voy a sacar fue la respuesta, para que sea sirvienta como yo, que es lo último. Yo aguanto esto sacrificándome por mis hijas, pero para ellos espero otra $\operatorname{cosa}^{114}$.

No era la primera vez que las visitadoras sugerían el egreso de las niñas. En 1951, por ejemplo, le habían propuesto la posibilidad de una reunificación familiar, ante lo que ella "suplica se prolongue la internación de sus 2 hijas, hasta ver su con la iniciación de su hijo mayor en el trabajo, consiguen evolucionar en forma más favorable para su egreso, el que tan pronto pueda hacerlo según dice, será solicitado"15. Mientras tanto, expresaba su agradecimiento con la Dirección de Asistencia Social, "por lo que ha representado para ella la ayuda prestada" 16 .

Lo llamativo del informe de 1953 es que, a diferencia de lo que se observa en los anteriores, Jacinta adoptó un tono menos estratégico en su conversación con la visitadora. No solo mostró con menos reparos los motivos por los que deseaba que sus hijas permanecieran en el Unzué, sino que habló más abiertamente de sus empleadores. Si hasta ese momento había predominado la gratitud al referirse a ellos (dos años antes la trabajadora social escribió "está muy contenta con la generosidad de la familia Iturralde y del buen trato que de ellos recibe"17), aquí los llamaba mezquinos y sostenía que una de sus hijas estaba loca.

En su informe, la visitadora "confesó" que Jacinta le había resultado poco agradable y desagradecida. Sostuvo que le había explicado que "estaba equivocada al creer que su sueldo eran $\$ 350$ pues estaba ganando arriba de \$1000 y todavía le permitían llevar a las menores de vacaciones", y se lamentó que no entrara en razones respecto de las perspectivas de sus hijas ${ }^{18}$. Decía que había intentado hacerla "reflexionar [respecto de que] estaba muy bien que cada uno aspirara a lo mejor, pero que por lo general las tareas que cada uno realiza deben estar en orden a su capacidad"19. La visitadora había recomendado la reunificación familiar. Como otras que tomarían el caso más adelante, entendía que lo ideal era que "pudiera reunirse la familia y cooperar con el esfuerzo común a su mutuo sostén, constituyendo nuevamente el hogar"20.

Jacinta había solicitado a fines de 1953 que se les permitiera a sus hijas cursar estudios de enfermería, lo que nos habilita a reflexionar en torno de las aspiraciones laborales y sociales que las mujeres trabajadoras podían tener para sí y para sus hijos. A mediados del siglo pasado, el mercado laboral ofrecía distintas alternativas para las mujeres, tanto en el sector industrial como en los servicios (Lobato, 2007; Queirolo, 2018), pero algunas, como la enfermería, suponían no solo mejores condiciones de trabajo, sino que también estaban revestidas de cierta distinción y de la posibilidad de un ascenso social en una profesión asociada en términos simbólicos con lo femenino (Ramacciotti, 2019) ${ }^{21}$.

La insistencia de las visitadoras en torno de la posibilidad de la reunificación familiar no cejó, pero Jacinta tampoco lo hizo. En mayo de 1954, el informe ambiental consignaba que ella "solicita de esta Dirección se le contemple las posibilidades, a fin de que sus hijas puedan terminar sus respectivos oficios, de manera tal que cuando salgan de sus Institutos, puedan ganarse la vida mejor de lo que ella efectúa, no desearía que estas tuvieran que trabajar de sirvienta (sic)"22. Poco tiempo después, en efecto, se dispuso el traslado de Rita y Mabel desde el Instituto Unzué al Instituto José María Pizarro y Monje para su formación profesional.

Rita había manifestado que no le interesaban los estudios, en cambio Mabel manifestó que le interesaba la enfermería. Sin embargo, sería Rita quien cursara el primer año de enfermería en la Maternidad Sardá, mientras que Mabel realizaba un curso de Corte y Confección. Ambas, además, asistirían a un taller de costura y ropería en el hogar en el que vivían. Ahora bien, más allá de los pedidos de Jacinta, la mala conducta de Rita haría que sus posibilidades se redujeran. A mediados de agosto, las autoridades dieron a Jacinta dos opciones: firmar el traslado de Rita a otro hogar en el que se la prepararía para "su reintegro al medio común"23, o aceptar su egreso del sistema. A fin de ese mes, Jacinta retiró a Rita del hogar en que se encontraba. Mabel siguió allí casi un año más, hasta junio de 1955, cuando también fue retirada por su madre. 


\section{SERVICIO DOMÉSTICO Y MATERNIDAD}

¿Qué relevancia historiográfica tienen las historias de Jacinta y las de los cientos de mujeres que a fines de los años cuarenta acudieron a la SB para solicitar la internación de sus hijos? Si bien los estudios históricos sobre la maternidad en nuestro país son abundantes, por lo general las investigaciones han dado un espacio relativamente menor a las experiencias de las madres, en parte debido a las dificultades para encontrarlas en las fuentes consultadas. Los legajos de menores contienen información que permite explorar las formas en las que mujeres como Jacinta vivían la maternidad y los márgenes de agencia que tenían. Permiten, además, problematizar la relación entre trabajo y maternidad.

Como Jacinta, una importante proporción de las mujeres que solicitaban la internación de sus hijos declaraban desempeñarse como "sirvientas", "mucamas" o "domésticas". Incluso cuando algunas de estas declaraciones debieran leerse con ciertos reparos, su recurrencia no es llamativa: para mediados de siglo el servicio doméstico era la ocupación más frecuente de las mujeres que participaban del mercado de trabajo (Wainerman, 2007; Lobato, 2007). Ahora bien, quizás esta ocupación también sea indicativa de las particulares experiencias de maternidad de quienes realizaban este tipo de trabajo.

En Argentina, en 1947, las mujeres empleadas en el servicio doméstico según los registros oficiales del gobierno, que tienden a subestimar el trabajo femenino y este sector en particular (Hutchison, 2001), superaban las 376.000, y representaban alrededor del $30 \%$ de aquellas que participaban del mercado de trabajo. Para 1960, ese porcentaje se reduciría al niveles en torno al $20 \%$, y se mantendrían con ligeras variaciones al menos hasta 1980 (Gogna, 1993; Zurita, 1997). Para entonces había disminuido la cantidad de hogares que empleaba a más de una persona de servicio, y habían desaparecido muchas de las posiciones más especializadas, como las de ama de llaves, mayordomo, etc. (Cárdenas, 1986). Asimismo, se había producido una creciente feminización del servicio doméstico, y habían desaparecido prácticamente las ocupaciones masculinas (Pérez, Cutuli y Garazi, 2018). Por otro lado, la alta proporción de migrantes ultramarinos que podía encontrarse en el sector a principios de siglo (rondaba el $50 \%$ ) se redujo en favor de las migrantes internas y de países limítrofes. En el mismo período, el empleo "cama afuera" comenzó a desplazar al sin retiro (Gogna, 1993).

Las condiciones materiales de vida y de trabajo también se vieron influidas por la sanción de algunos, aunque limitados, derechos laborales para quienes se desempeñaban en esta ocupación. En 1946 se incluyó al personal del servicio doméstico en el régimen del salario anual complementario. Unos años después, en 1949, se les reconoció el descanso semanal obligatorio. Más adelante, en 1956 se sancionó el Decreto Ley 326, que estableció derechos como la licencia por enfermedad, las vacaciones pagas, la limitación de la jornada de trabajo, entre otros. Esas protecciones, sin embargo, eran limitadas (Pérez, Cutuli y Garazi, 2018). Una de las notables ausencias en el Decreto Ley 326 fue la de la licencia por maternidad, probablemente vinculada a la representación de las trabajadoras como mujeres jóvenes, solteras y sin responsabilidades familiares.

Si bien no tenemos datos estadísticos para confrontar estas representaciones, el análisis de juicios laborales -realizado en el marco de una investigación previa- nos permite saber que, para mediados de siglo, no eran pocas las empleadas domésticas que habían formado un núcleo familiar propio, aunque en su mayoría se trataba de mujeres que trabajaban con retiro (Pérez, Cutuli y Garazi, 2018). Sabemos también que a quienes lo hacían sin retiro y tenían hijos a su cargo se les demandaba gratitud y deferencia, y se les negaba en ocasiones sus derechos laborales. Los empleadores que aceptaban la presencia del niño o la niña en sus hogares solían argüir que los habían tratado como hijos propios, alimentándolos, vistiéndolos y encargándose de su educación, lo que los ubicaba como los adultos responsables de esos niños (Pérez, 2018). ¿Qué lugar les cabía a las madres en esos casos? ¿Qué alternativas tenían?

Algunas buscaban un empleo que les permitiera conciliar mejor la búsqueda de una entrada de dinero y el cuidado de sus hijos. En los legajos es posible ver las trayectorias ocupacionales de las madres que internaban a sus hijos, 
y no era poco frecuente que del empleo doméstico pasaran a uno en una fábrica o taller, o a distintas formas de trabajo a domicilio. La familia extensa podía ser también un recurso: muchas enviaban a alguno de sus hijos a vivir con un pariente de mejor pasar; otras reorganizaban sus estrategias residenciales para compartir los gastos y el cuidado. Sin embargo, esas estrategias podían no ser suficientes y, como en el caso de Jacinta, la internación de los hijos en una institución podía aparecer como una solución.

¿Qué tipo de experiencias de la maternidad suponía el servicio doméstico? ¿Qué restricciones imponía en términos de los vínculos familiares que las trabajadoras podían mantener? La historia de Jacinta, y las de otras Jacintas que pueblan los legajos de menores permite verificar aquello que observaba Rickie Solinger en torno de que la maternidad (o al menos una forma de ejercerla) es un privilegio de clase (Solinger en Boris y Kleinberg, 2003, p. 106). Aunque otras ocupaciones habituales entre las mujeres de sectores populares también podían dificultar la convivencia de madres e hijos, en el caso del servicio doméstico -y quizá también el de otros "trabajos íntimos", para tomar la categoría de Eileen Boris y Rachel Salazar Parreñas (2010)- las restricciones parecen haber sido más frecuentes.

Realizar este tipo de trabajo no era un impedimento para la maternidad, pero sí para ciertas formas de ejercerla. El modelo de maternidad hegemónico, que suponía la convivencia con los hijos, no era fácil de sostener. Sin embargo, muchas trabajadoras desarrollaron otras estrategias de cuidado. El caso de Jacinta muestra cómo algunas de ellas permitían resignificar el sentido de ser una buena madre; también evidencia sus limitaciones.

En los legajos de Rita y Mabel se registran imágenes contrastantes en torno a la maternidad: para quienes trabajaban en la Dirección de Asistencia Social, siempre que fuera posible, había que intentar mantener la "unidad de la familia"; para Jacinta, en cambio, la prioridad estaba en la posibilidad de que sus hijas tuvieran una formación profesional que ampliara sus posibilidades laborales. Aunque espaciadas, sus visitas y el tiempo que podía compartir con ellas en los períodos de vacaciones escolares le permitieron incidir en el destino de sus hijas de un modo en que otras mujeres no pudieron hacerlo. En efecto, a diferencia de otras jóvenes de la misma edad internadas en el mismo hogar, Rita y Mabel no fueron colocadas para el servicio como parte de su trayectoria en el sistema de minoridad, sino que permanecieron en el hogar recibiendo formación en oficios manuales. En el proceder de Jacinta puede entreverse una forma particular de entender qué significaba ser una buena madre: garantizar una buena educación para sus hijas, incluso si eso suponía sacrificarse con un trabajo que no quería, tener lejos a sus hijas y soportar condiciones duras para poder verlas periódicamente. En eso consistía "el fervor y el cariño de una madre pobre".

Estas historias también nos permiten ver cómo tanto las trabajadoras como sus hijos eran muchas veces incorporados a la familia de los empleadores, aunque dicha integración operaba como una forma de subordinación y contribuía a delinear las desigualdades de clase en el mundo doméstico, un mundo de hecho ordenado por el estatus y las relaciones jerárquicas, maternalistas (Pite, 2011). En el caso de Jacinta esto resulta visible de distintas maneras: los empleadores que se habían negado a que las niñas vivieran en su casa le permitían llevar a Mabel y Rita consigo durante las vacaciones e incluso que durmieran en la habitación de sus hijas. Al mismo tiempo, se jactaban de ser "la única familia" que ellas conocían. La inclusión de Jacinta, y (¿a veces?) la de sus hijas en el sistema familiar de los empleadores estaba signada por la dependencia y la inferiorización.

Esto resulta especialmente significativo en tanto eran las empleadas domésticas como Jacinta la que en muchos casos desarrollaban la labor cotidiana del cuidado de los hijos de los empleadores. Como hemos mostrado en otro texto con Santiago Canevaro, en el contexto de la judicialización de los conflictos originados en la falta de observación de los derechos laborales de las trabajadoras, ellas muchas veces apelaban a ese cuidado para mostrar la calidad de su trabajo, y su propia estatura moral (Pérez y Canevaro, 2015), mostrándose como mejores madres de los hijos de sus empleadoras que las empleadoras mismas. La maternidad era un sitio disputado, tanto en relación a quién podía ocuparlo, como a qué implicaba hacerlo. 
A mediados del siglo XX, el servicio doméstico suponía límites específicos al tipo de vínculos familiares que las trabajadoras podían entablar, y, sobre todo, sostener. Quizás por eso para Jacinta ser una buena madre fuera, ante todo, evitar que sus hijas terminaran siendo "sirvientas".

\section{Consideraciones finales: historias de Jacintas, Preguntas Para la Historia}

¿Cuáles son las posibilidades historiográficas que brinda el archivo de la SB y en particular los legajos de menores para pensar la historia social del trabajo desde una perspectiva de género? Los legajos de menores nos acercan no solo a materiales que documentan las vidas de las trabajadoras, sino que permiten acceder, aun de manera mediada, a su voz, presente en las cartas de las madres a sus hijos, los informes de las visitadoras sociales, los pedidos ante las autoridades, etc. La recurrencia con la que aparecen trabajadoras domésticas en los legajos es significativa en términos historiográficos por la dificultad de hallarlas en los registros documentales, pero más aún porque la información que conservan permite pensarlas más allá de las fronteras del hogar, en una línea que retoma algunas de las discusiones más recientes e innovadoras en el campo de estudios sobre el servicio doméstico ${ }^{24}$. Si estos estudios se habían centrado en la relación de las trabajadoras con sus empleadores, en las condiciones de trabajo y en las posibilidades de sindicalización, estas fuentes permiten pensar las formas en que este empleo condicionaba la vida de las trabajadoras más allá de lo laboral. Puntualmente, remiten a sus experiencias de maternidad y sugieren preguntas por la relación entre el servicio doméstico y las relaciones familiares que quienes lo desempeñaban podían establecer.

Las reconstrucciones históricas de las condiciones materiales de vida de los sectores populares se han enfocado en cuestiones como las estrategias habitacionales o el monto de los salarios y su capacidad de compra. Los estudios sobre ocupaciones específicas, por otra parte, han tendido a hacer foco en la vida de las trabajadoras y los trabajadores dentro del ámbito laboral. Aunque recientemente la historia de las comunidades obreras ha ganado impulso - llamando la atención sobre otras dimensiones de la sociabilidad de las trabajadoras y los trabajadores-, este tipo de abordajes no se ha centrado específicamente en la situación de las trabajadoras madres, y, además, difícilmente podrían constituir el enfoque apropiado para pensar la vida de trabajadoras que, por sus condiciones laborales, se encontraban relativamente aisladas las unas de las otras.

Las experiencias registradas en los legajos de menores permiten no solo aportar al conocimiento histórico de las formas en que la maternidad se articula con la clase, e incluso el origen migratorio, sino contribuir a historizar la relación entre ciertas ocupaciones y los vínculos familiares que quienes las desempeñaban podían sostener. Las investigaciones sobre las cadenas globales de cuidado (Ehrenreich y Hochschild, 2004) que se han desarrollado en las últimas décadas han problematizado esta relación, pero lo han hecho desde una mirada que no siempre pone en perspectiva los modelos de maternidad y familia proyectados a partir de las experiencias de mujeres blancas de clase media del Norte Global.

Las preguntas que surgen de la lectura de estas fuentes ponen en un primer plano que tanto la esfera del empleo como la de la familia forman parte de los mundos del trabajo. Y aun más, ponen en cuestión la mirada sociocentrada sobre el trabajo doméstico y los cuidados, en la medida en que destacan situaciones en las que el trabajo remunerado se desarrollaba en el interior de hogares privados y los cuidados a los hijos propios tenían lugar en el ámbito público. Las historias de las mujeres que acudían a la SB fuerzan un distanciamiento de esos modelos y remiten a otras formas de ser madres en el marco de constricciones sociales específicas. En este sentido, a su vez, no solo muestran restricciones sino también la agencia histórica de mujeres que, a pesar de esos condicionamientos, lograban incidir en el destino de sus hijos dentro del sistema de minoridad.

\section{Bibliografía}

Alayón, N. (1992). La historia del trabajo social en Argentina. Buenos Aires: Espacio. 
Allemandi, C. (2017). Sirvientes, criados y nodrizas. Una historia del servicio doméstico en la ciudad de Buenos Aires (fines del siglo XIX y principios del XX). Buenos Aires: Teseo-San Andrés.

Andújar, A., Caruso, L., Gutiérrez, F., Palermo, S., Pita, V., y Schettini, C. (2016). Vivir con lo justo. Estudios de historia social del trabajo en perspectiva de género. Argentina, siglos XIX y XX. Rosario: Prohistoria.

Aversa, M. (2014). Un mundo de gente menuda. El trabajo infantil tutelado. Ciudad de Buenos Aires, 1870-1920 (Tesis Doctoral). Universidad de Buenos Aires, Buenos Aires.

Baldassar, L. (2008). Missing Kin and Longing to be Together: Emotions and the Construction of Co-presence in Transnational Relationships. Journal of Intercultural Studies, 29(3), 247-266.

Billorou, M. J. (2007). Madres y médicos en torno a la cuna. Ideas y prácticas sobre el cuidado infantil (Buenos Aires, 1930-1945). La Aljaba. Segunda Época, XI, 167-192.

Billorou, M. J. (2008). "Mujeres que trabajan". Nuevos y viejos mandatos hacia las profesiones femeninas en el Territorio Nacional de La Pampa durante la primera mitad del siglo XX. Actas de las III Jornadas de Historia de la Patagonia, Argentina.

Blum, A. (2009). Domestic economies. Family, Work, and Welfare in Mexico City, 1884-1943. Lincoln and London: University of Nebraska Press.

Boris, E., y Kleinberg, S. (2003). Mothers and Other Workers. (Re) Conceiving Labor, Maternalism and the State. Journal of Women's History, 15(3), 90-117.

Boris, E. \& Salazar Parreñas, R. (2010). Intimate Labors. Cultures, Technologies and the Politics of Care. Sanford: Stanford University Press.

Bracamonte, L. (2014). La rénovation des études sur l'assitance sociale. Les femmes et la sphère publique en Argentine du début du XXe siècle. Cahier d'histoire immediate, 46, 113-127.

Bracamonte, L. (2015). Género, políticas sociales y Estado: los estudios sobre las proveedoras de asistencia social en la Argentina de fines del siglo XIX y principios del siglo XX. En M. J. Caviglia y E. Ardanaz (eds.), Perspectivas y enfoques de género en las investigaciones de las Ciencias Sociales (pp. 15-24). Bahía Blanca: Hemisferio Derecho.

Cárdenas, I. (1986). Ramon a y el robot. El servicio doméstico en barrios prestigiosos de Buenos Aires (1895-1985). Buenos Aires: Ediciones Búsqueda.

Ciafardo, E. (1990). Las damas de beneficencia y la participación social de las mujeres en la ciudad de Buenos Aires, 1880-1920. Anuario del IEHS, 5, 161-170.

Cicerchia, R. (1994). Las vueltas del torno: claves de un malthusianismo popular. En L. Fletcher (comp.), Mujeres $y$ cultura en la Argentina del siglo XIX (pp. 196-206). Buenos Aires: Feminaria.

Dalla-Corte Caballero, G. (2013). El Archivo de Señales del Hogar del Huérfano de Rosario: niñez, identidad y migración 1879-1914. Rosario: Prohistoria.

de Paz Trueba, Y. (2007). El ejercicio de la Beneficencia. Espacio de prestigio y herramienta de control social en el centro y sur bonaerense a fines del siglo XIX. História, 26(2), 366-384.

de Paz Trueba, Y. (2010). Mujeres y esfera pública. La campaña bonaerense entre 1880 y 1910. Rosario: Prohistoria.

Di Leonardo, M. (1987), The Female World of Cards and Holidays: women, Families and the Work of Kinship. Signs, 12(3), 440-453.

Di Liscia, M. S., y Billorou, M. J. (2005). Cuadernos de las Visitadoras de Higiene. Fuentes para una historia de género regional. Santa Rosa: Instituto Interdisciplinario de Estudios de la Mujer.

Ehrenreich, B. \& Hochschild, A. (2004). Global Woman. Nannies, Maids and Sex Workers in the New Economy. Nueva York: Henry Holt and Company.

Facciuto, A. (2003). El surgimiento de la política social en Argentina. Revista de Humanidades Tecnológico de Monterrey, 14, 165-205.

Fuchs, R. (2003). Beneficencia y bienestar. En D. Kertzer y M. Barbagli (comps.), Historia de la Familia Europea (Volumen II, pp. 243-296). Barcelona: Paidós. 
García Jordán, P., y Dalla-Corte Caballero, G. (2006). Mujeres y sociabilidad política en la construcción de los Estados nacionales. En I. Morant (dir.), Historia de las Mujeres en España y América Latina (Tomo 3, pp. 559-583). Madrid: Cátedra.

Gavrila, C. (2018). Hermosear y vigilar. Las Visitadoras de Higiene Social de la Universidad Nacional de La Plata en el proceso de institucionalización del trabajo social en la Argentina (1922-1948) (Tesis de Maestría). Universidad Nacional de La Plata, La Plata.

Gogna, M. (1993). Empleadas domésticas en Buenos Aires. En E. Chaney y M. García Castro (eds.), Muchacha, cachifa, criada, empleada, empregadinha, sirvienta y...más nada (pp. 81-98). Venezuela.

Golbert, L., y Roca, E. (2010). Desde la Sociedad de Beneficencia a los derechos sociales, Revista de trabajo. Segunda época, 6(8), 29-52.

Guy, D. (2011). Las mujeres y la construcción del Estado de Bienestar. Caridad y creación de derechos en Argentina. Buenos Aires: Prometeo.

Hutchison, E. (2001). Labors Appropriate to Theirsex. Gender, Labor, and Politics in Urban Chile, 1900-1930. Durham and London: Duke University Press.

Lobato, M. (2007). Historia de las trabajadoras en la Argentina (1869-1960). Buenos Aires: Edhasa.

Milanich, N. (2009). Children of Fate. Childhood, Class and the State in Chile, 1850-1930. Durham and London: Duke University Press.

Moreno, J. L. (ed.) (2000). La politica social antes de la politica social: caridad, beneficiencia y poli\#tica social en Buenos Aires, siglos XVII a XX. Buenos Aires: Trama editorial/Prometeo libros.

Moreyra, B. (2009). Cuestión social y políticas sociales en la Argentina. La modernidad periférica. Córdoba, 1900-1930. Bernal: Universidad Nacional de Quilmes.

Pérez, I. (2018). ¿Criadas o trabajadoras? Lenguajes, representaciones y estrategias frente a la justicia laboral (Buenos Aires, 1956-1970). Revista Historia y Justicia, 11, 101-124.

Pérez, I. \& Canevaro, S. (2015). Languages of affection and rationality: household workers' strategies before the Tribunal of Domestic Work (Buenos Aires, 1956-2013). International Labor and Working-Class History, 88, 2015, 130-149.

Pérez, I., Cutuli, R., y Garazi, D. (2018). Senderos que se bifurcan. Servicio doméstico y derechos laborales en la Argentina del siglo XX. Mar del Plata: Eudem.

Pita, V. (2009). Nos termos de suas benfeitoras: encontros entre trabalhadoras e as senhoras da Sociedade de Beneficência, Buenos Aires, 1852-1870, Mundos do Trabalho, I, 41-64.

Pita, V. (2012). La casa de las locas. Una historia social del Hospital de Mujeres Dementes. Buenos Aires, 1852-1890. Rosario: Prohistoria.

Pita, V. (2014). De negociaciones cotidianas y de posibilidades históricas: una aproximación a los intercambios entre médicos y trabajadoras. Buenos Aires, 1870-1940. Anuario de Historia Regional y de las Fronteras, 19(2), 365-390.

Pita, V. (2015). El policía, el juez, la familia y el posadero o cómo algunos porteños entendieron de demencias y locuras. Buenos Aires, 1970-1890. Trashumante. Revista Americana de Historia Social, 5, 84-103.

Pite, R. (2011). Entertaining inequalities: Doña Petrona, Juanita Bordoy, and Domestic Work in Mid-TwentiethCentury Argentina. Hispanic American Historical Review, 91(1), 97-128.

Queirolo, G. (2018). Mujeres en las oficinas. Trabajo, género y clase en el sector administrativo (Buenos Aires, 1910-1950). Buenos Aires: Biblos.

Ramacciotti, K. (2019). La profesionalización del cuidado sanitario. La enfermería en la historia argentina. Trabajos y comunicaciones, $49, \mathrm{e} 081$.

Stanley, L. (2004). The Epistolarium: On Theorizing Letters and Correspondences. Auto/Biography, 12, 201-235.

Suriano, J. (2004). Los historiadores y el proceso de construcción del Estado social. En J. Bertranou, J. M. Palacio y G. Serrano (comps.), En el pais del no me acuerdo. (Des)memoria institucional e historia de la política social en la Argentina (pp. 33-58). Buenos Aires: Prometeo. 
Villalta, C. (2012). Entregas y secuestros. El rol del Estado en la apropiación de niños. Buenos Aires: Ediciones del Puerto. Wainerman, C. (2007). Mujeres que trabajan. Hechos e ideas. En S. Torrado (ed.), Población y bienestar en la Argentina delprimero al segundo Centenario. Una Historia Social del siglo XX (Tomo II, pp. 325-352). Buenos Aires: Edhasa.

Zapiola, C. (2010). La Ley de Patronato de Menores de 1919: ¿̇una bisagra histórica? En L. Lionetti y D. Míguez (comps.), Las infancias en la historia argentina. Intersecciones entre prácticas, discursos e instituciones (1890-1960) (pp. 117-132). Rosario: Prohistoria.

Zapiola, C. (2014). Un lugar para los menores. Patronato estatal e instituciones de corrección, Buenos Aires, 1890-1930 (Tesis Doctoral). Universidad de Buenos Aires, Buenos Aires.

Zurita, C. (1997). Trabajo, servidumbre y situaciones de género. Algunas acotaciones sobre el servicio doméstico en Santiago del Estero, Argentina. Programa de Investigaciones sobre Trabajo y Sociedad (PROIT) del Instituto de Desarrollo Social (INDES) de la Universidad Nacional de Santiago del Estero (UNSE).

\section{Notas}

1. Archivo General de la Nación (AGN), Archivo Intermedio (AI), Fondo Secretaría de Niñez, Infancia y Familia (SNAF), Legajo (L) 59.981. Los nombres de las actoras y los actores han sido cambiados para preservar su privacidad.

2. Si bien en los legajos de Rita y Mabel no se conserva la solicitud inicial de Jacinta y la admisión fue realizada por la Dirección de Asistencia Social, podemos deducir que esto fue así porque sus legajos se conservaron dentro del Fondo Sociedad de Beneficencia. Posiblemente se trate de un período de transición que se extiende hasta los primeros meses de 1949, de cuando datan los últimos legajos conservados en este fondo. Aquellos iniciados posteriormente por la Dirección de Asistencia Social están conservados por la Secretaría Nacional de Niñez, Adolescencia y Familia, dependiente del Ministerio de Desarrollo Social de la Nación, y no están disponibles para la consulta pública. Además, sabemos por la lectura de otros legajos que era habitual que entre la solicitud y la admisión mediaran algunos meses.

3. La ortografía es la del texto original.

4. Como se menciona abajo, la Sociedad de Beneficencia fue disuelta en 1948. Sin embargo, los legajos se extienden por un período mayor, en tanto siguen la trayectoria del niño o la niña hasta su egreso del sistema de minoridad. En el caso tomado en este artículo, los legajos de las hijas de Jacinta nos permiten seguir su trayectoria hasta 1955.

5. Hasta 1880 dependió del gobierno de la provincia de Buenos Aires. En ese momento cambió su nombre a Sociedad de Beneficencia de la Capital (Pita, 2012).

6. Utilizo el término colocaciones domésticas para nombrar las prácticas que suponían el intercambio de trabajo doméstico y de cuidados realizado por niñas y jóvenes a cambio de ser alojadas, alimentadas, vestidas y educadas. Muchas veces, ese intercambio suponía también una remuneración, aunque solía ser menor que la pactada para las trabajadoras adultas. Las colocaciones domésticas podían estar mediadas institucionalmente, o ser pactadas de manera privada entre los familiares de la niña o joven y sus guardadores. Como han mostrado algunas investigaciones recientes (Aversa, 2014; Allemandi, 2017), este tipo de colocación era frecuente en las primeras décadas del siglo XX. Aunque para mediados de siglo su frecuencia disminuyó (Villalta, 2012), en los legajos de la SB, así como en expedientes de los Tribunales de Menores de la Provincia de Buenos Aires, es posible ver que todavía a mediados de siglo era una práctica relativamente frecuente. En este sentido, resulta significativo que incluso a fines de los años sesenta, en buena parte de las colocaciones interviniera la Bolsa de Trabajo dependiente del Consejo del Menor, y que las mismas estuvieran supervisadas por el Consejo. La principal diferencia que se observa respecto de períodos previos en los casos de las colocaciones mediadas institucionalmente es un aumento en la edad de las niñas colocadas, superior a los catorce años marcados legalmente desde 1924 como edad mínima para el empleo en el servicio doméstico.

7. Esto tendría especial relevancia luego de la sanción de la primera ley de adopción en 1948, que supuso una reactivación de los debates en relación a la patria potestad y a los casos en los que podía perderse. La ley Agote, de 1919, había marcado un avance del Estado sobre los derechos de los progenitores, hasta entonces considerados naturales, que podían perderse ante el abandono físico de los hijos. Sin embargo, si hasta los años treinta la jurisprudencia tendía a sostener que la internación de un niño en una de las instituciones dependientes de la SB suponía la pérdida de la patria potestad, durante los años cuarenta algunos magistrados comenzaron a ver esa doctrina como "excesiva", y empezaron a admitirse circunstancias, como la extrema pobreza, en las que una decisión así podía ser justificada. Como muestra Carla Villalta (2012), en los juicios en los que los progenitores se oponían a una posible adopción, el contacto que los padres y madres hubiesen mantenido con sus hijos luego de haberlos internado resultaba clave para establecer si había habido o no abandono. Lo que es más, si se miran las fuentes citadas por Villalta, resulta evidente que el "cariño" hacia los hijos era un elemento recuperado de manera recurrente por los jueces a la hora de dictar sentencia.

8. AGN, AI, SNAF, L 59982, F. 5. 
9. Idem, F. s/n.

10. Se toma la ortografía del texto original. AGN, AI, SNAF, L 59982, F. 23.

11. AGN, AI, SNAF, L 59.981, F. s/n.

12. Idem, F. $s / n$.

13. AGN, AI, SNAF, L 59.981, F. s/n. Informe del 18 de diciembre de 1953.

14. Ídem, F. s/n.

15. AGN, AI, SNAF, L 59.982, Foja 26.

16. Idem.

17. Informe de mayo de 1951, AGN, AI, SNAF, L 59.982, Foja 26.

18. AGN, AI, SNAF, L. 59.981, Foja s/n.

19. Idem, Foja s/n.

20. f. 84 .

21. Esto puede permitir desarrollar futuras investigaciones sobre la percepción de las mujeres trabajadoras de las distintas ocupaciones que en las que podían desempeñarse a mediados del siglo XX.

22. f. 89

23. f. 90

24. En septiembre de 2017 tuvo lugar en la Universidad de Oxford un encuentro titulado "Beyond the Home: New Histories of Domestic Servants", en el que se presentaron más de 40 investigaciones que recuperaban las formas en que los y las trabajadoras interactuaron y moldearon su entorno, en dimensiones como la vida familiar y marital, su participación comunitaria, su uso del tiempo libre, entre otras. Los resultados de esta conferencia serán próximamente publicados, pero los avances disponibles permiten ver la potencia de este tipo de aproximaciones para renovar los modos de abordar la historia del servicio doméstico. En Argentina, el libro de Cecilia Allemandi (2017) también constituye un aporte central para este tipo de abordaje, en tanto trasciende las fronteras de lo que ocurría a las domésticas en su lugar de trabajo, para pensarlas como parte del complejo entramado urbano y social de la Buenos Aires de entresiglos. 